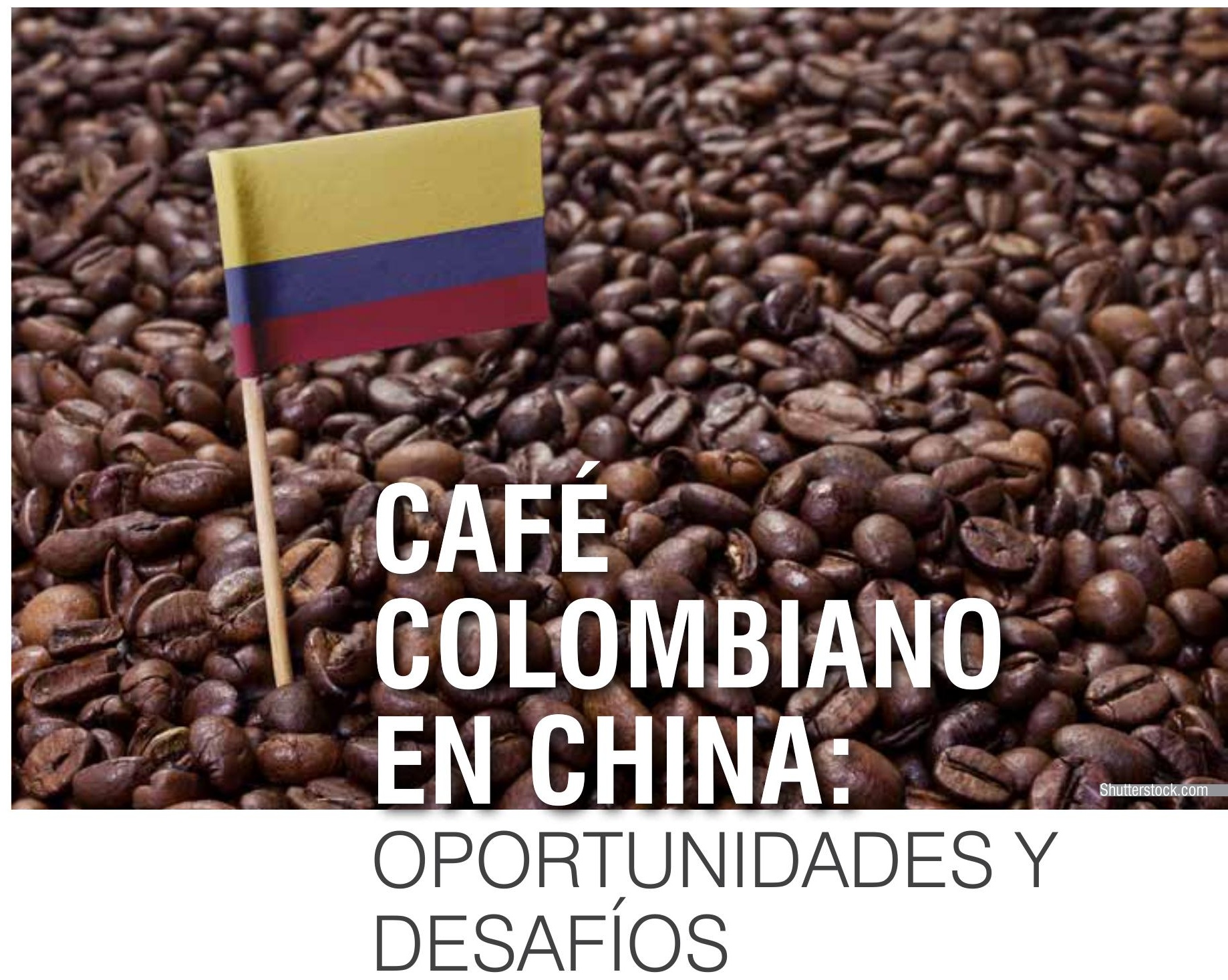

Colombian coffee in China: Challenges and Opportunities

\title{
doi: 10.17230/map.v4.i6.06
}

\section{>> Mateo Jiménez Posada \\ Universidad EAFIT \\ mjimen14@eafit.edu.co}

\section{Laura Gómez Gómez}

Maria Arango Roldán

\section{Lorena Gómez Castaño}

Gabriela Palacios Ramírez

Andrés Restrepo

Campuzano

\section{Sebastián Toro Restrepo}

Manuela Vasquez Ochoa

\section{Abstract}

This article aims to explore business opportunities and to broaden the vision of China as a potential market for Colombian coffee. This article is the product of the Asia Pacific Research group's work during 2014 and will be divided in two parts. The article in this edition includes a comprehensive assesment of the importance of the Chinese economy, its hot drinks market, and its coffee production and imports. The follow-up article will be included in the seventh edition of this magazine and will discuss coffee consumption trends among Chinese consumers; as well as two models (e-commerce and manufacturing) for the successful insetion of the Colombian coffee in the Chinese market. The follow-up article will also include an analysis of the strengths, weaknesses, opportunities and threats in order to evaluate the possibilities to strengthen Colombian coffee's position in the Chinese market. 


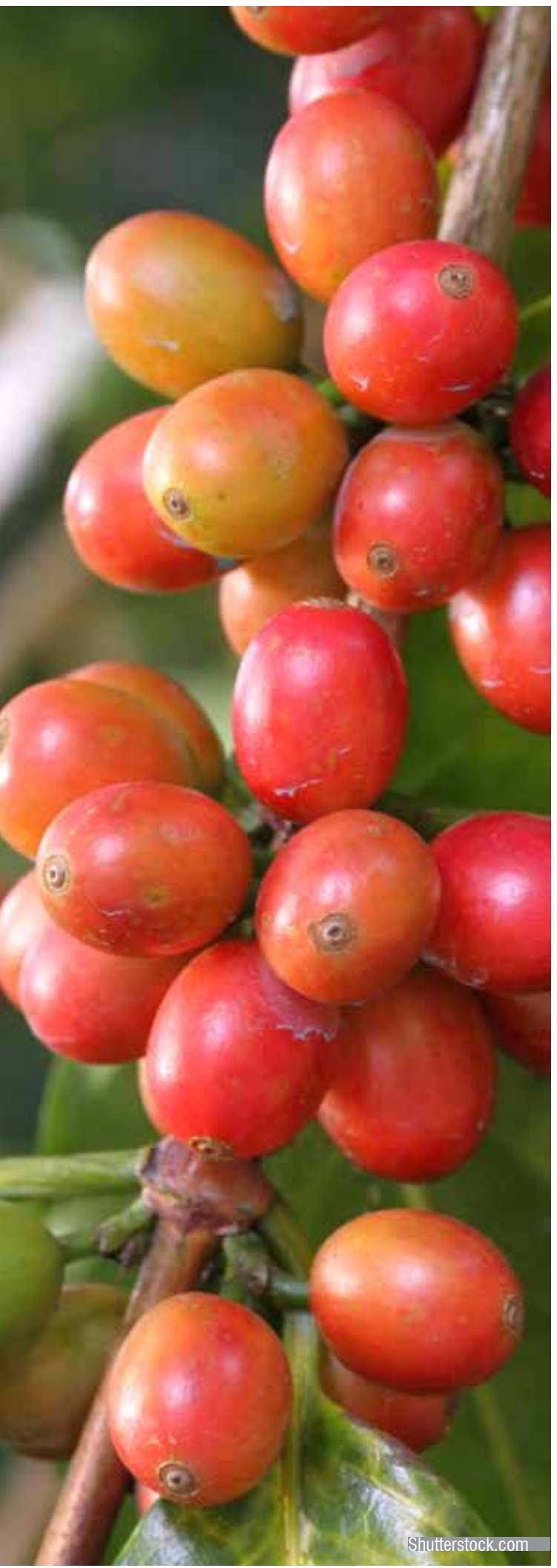

\section{Keywords}

Coffee, Colombia, China, international business, market strategy, consumer trends.

\section{Resumen}

El presente artículo busca explorar las oportunidades de negocio, así como ampliar la visión sobre China como mercado potencial para el café colombiano. Esta publicación hace parte de la divulgación de los resultados de la investigación del Semillero de Investigación de Asia Pacífico en el 2014 y será dividido en dos partes. El artículo en la presente edición incluye un análisis de la importancia de la economía de este país asiático, de su mercado de bebidas calientes, su producción cafetera e importaciones de este producto. El artículo tendrá continuación en la séptima edición de esta revista, donde se expondrán las principales tendencias del consumidor chino; y dos modelos (e-commerce y manufactura) para la penetración exitosa del café colombiano en el mercado chino. Asimismo en esta extensión se realizará un análisis de las fortalezas, debilidades, oportunidades y amenazas para evaluar las posibilidades de lograr un mayor posicionamiento del café colombiano en ese mercado.

\section{Palabras claves}

Café, Colombia, China, negocios internacionales, estrategia de mercado, tendencias del consumidor.

\section{Introducción}

La transformación económica, política, social y cultural de China ha sido uno de los grandes fenómenos de influencia mundial en los siglos XX y XXI. En este contexto, la industria colombiana y sus empresarios tienen el reto de lograr una inserción efectiva en el mercado asiático, así como las empresas chinas ya lo están haciendo en el colombiano. Sin embargo, existe un gran desconocimiento del mercado chino entre los emprendedores colombianos. La presente investigación se enfoca en la industria cafetera, en la medida que esta, como una de las principales actividades económicas del país, representa un nicho importante en el cual Colombia podría lograr un posicionamiento exitoso en este mercado asiático.

Teniendo en cuenta lo anterior, y con el fin de hacer un aporte a la industria, a los caficultores y al campo colombiano se resaltarán las múltiples oportunidades que existen en el gigante asiático. En este artículo se pretende responder a la pregunta ¿Cuáles son las potenciales oportunidades y dificultades que afrontaría Colombia para lograr un mayor posicionamiento de su café en el mercado chino?

Para resolver la misma, se expondrá el panorama general, donde se resalta la importancia de China como economía, y como mercado potencial de café para Colombia. En esta sección se presenta evidencia sobre cómo este país asiático, al constituir un mercado con perspectivas de crecimiento altas, y tener una economía estable y poderosa, cuenta con grandes oportunidades a aprovechar. A partir de esta apreciación, se muestra cómo la industria del café se podría beneficiar de este entorno positivo. La sección inicia presentando la situación actual del mercado del café en China, para luego poner en evidencia cómo la industria colombiana está desaprovechando las oportunidades y ventajas que tiene en este mercado. 
Asimismo, se estudiará el mercado de bebidas calientes en China haciendo énfasis en el café, con el fin de identificar oportunidades para la industria colombiana. Para esto, se inicia presentando la dinámica del mercado chino en este tipo de bebidas, su segmentación y demanda; con el fin de determinar si a pesar de la tan arraigada cultura del té, existe un lugar para otras alternativas como el café. Luego, se analizará la producción e industria cafetera china, para lograr precisar las principales tendencias de consumo.

\section{LA IMPORTANCIA DE CHINA COMO ECONOMÍA; MERCADO PO- TENCIAL DE CAFÉ PARA COLOMBIA}

La transformación de China en aspectos económicos, políticos, sociales y culturales ha sido uno de los grandes fenómenos de los siglos XX y XXI, no sólo porque es el mercado más grande y el mayor exportador del mundo en la actualidad, sino por la incidencia que su rápida evolución y proyección han tenido en el panorama mundial.

En el año 2013, la migración hacia las áreas urbanas ya era manifiesta; el país contaba con 1.357 millones de habitantes, de los cuales el 53\% estaba instalado en las ciudades, en su mayoria dedicados a contribuir con el crecimiento de la industria (National Bureau of Statistics of China, 2013; Datos Macro, 2013). En este mismo sentido, el PIB del año 2013 fue de US\$9.240 billones, un aumento de 7,7\% respecto a la cifra del año anterior (The World Bank, 2013). En cuanto al PIB per Capita, en este mismo año fue de US\$6.807 y la tasa de desempleo registró un 4,6\%. Las personas económicamente inactivas, es decir aquelos menores de 15 años o mayores de 64 años, representan un 37\% de la población. Por otro lado el desarrollo del sector manufacturero en China se ve reflejado en que la industria representa el 43,9\% del PIB, un porcentaje alto en comparación con otros pares asiáticos (véase tabla 1).

Tabla 1. Indicadores Económicos de China

\begin{tabular}{|c|c|c|c|c|c|}
\hline \multicolumn{9}{|c|}{ INDICADORES ECONÓMICOS DE CHINA } \\
\hline $\begin{array}{c}\text { Población (Millo- } \\
\text { nes), } 2013\end{array}$ & $\begin{array}{c}\text { PIB (Billones US } \\
\$ \text { ), } 2013\end{array}$ & $\begin{array}{c}\text { PIB per Cápita } \\
\text { (US\$), } 2013\end{array}$ & $\begin{array}{c}\text { Tasa de Desempleo, } \\
2013\end{array}$ & $\begin{array}{c}\text { Porcentaje población } \\
\text { dependiente, } 2013\end{array}$ & $\begin{array}{c}\text { Porcentaje po- } \\
\text { blación Urbana, } \\
2013\end{array}$ \\
$\begin{array}{c}\text { Industria como } \\
\text { porcentaje PIB, } \\
2013\end{array}$ & 4,6 & 37 & 53 \\
\hline
\end{tabular}

Fuente: Elaborado por el Semillero de Estudios Asia Pacífico con datos tomados del Banco Mundial, 2015.

Adicionalmente, tanto las exportaciones como las importaciones del país han crecido constantemente en los últimos cinco años (véase gráfico 1). Los niveles de empleo, la inversión extranjera directa (IED) y las reservas internacionales han mantenido esta misma tendencia (véase gráfico 2) (National Bureau of Statistics of China, 2013). 
Gráfico 1. Exportaciones e importaciones de China (millones de dólares)

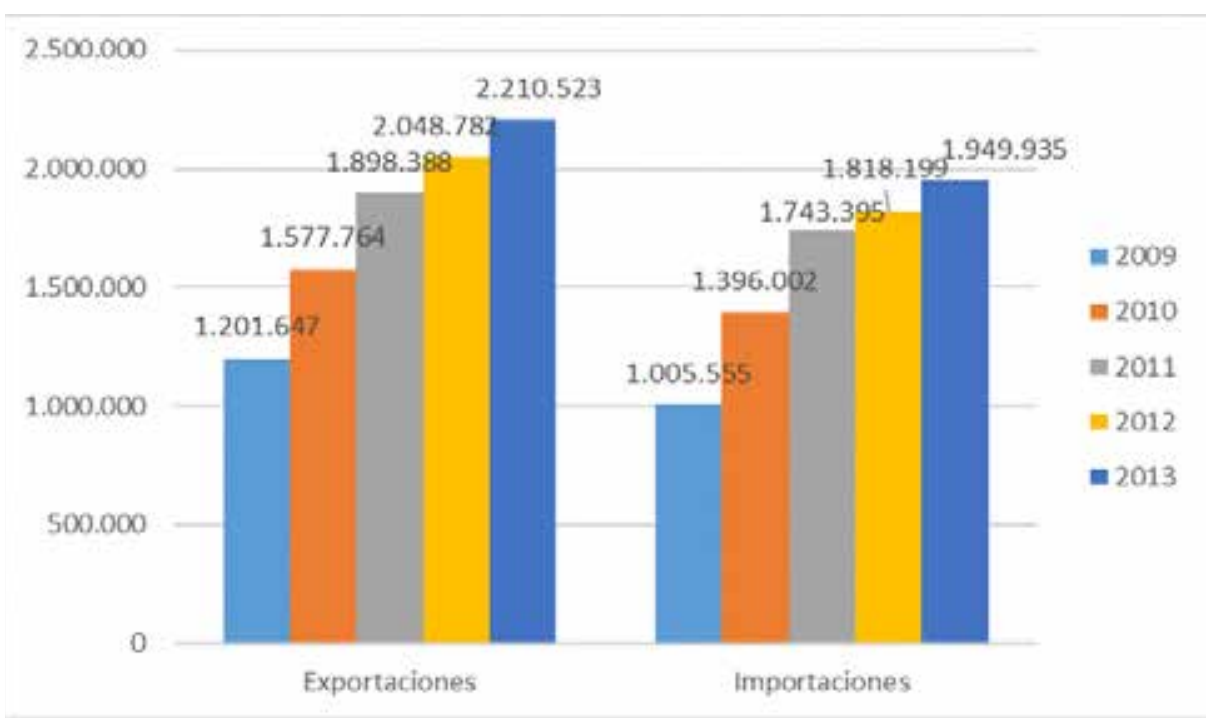

Fuente: Elaborado por el Semillero de Estudios Asia Pacífico con datos tomados del International Trade Center, 2013.

Gráfico 2. Inversión Extranjera Directa en China (miles de dólares)

140.000

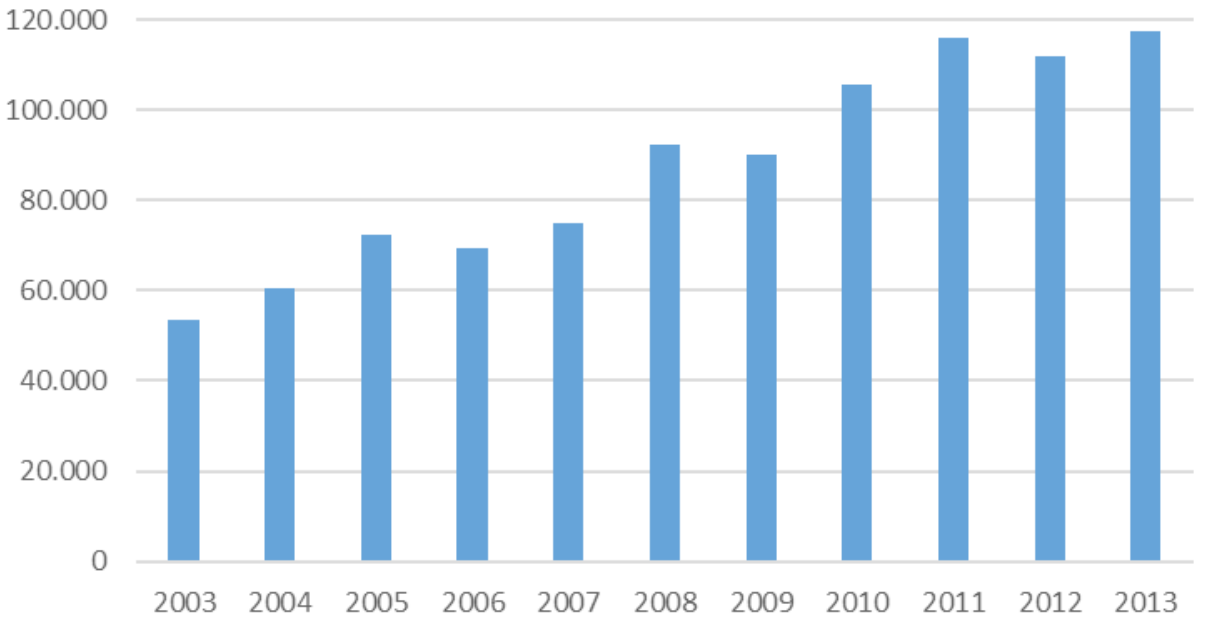

Fuente: Elaboración del Semillero de Estudios Asia Pacífico a partir de Echavarría Toro, 2013.

En términos comerciales, como lo mencionan Chen y Lombaerde (2013), el desarrollo comercial ha llevado a China a tener una política de liberalización de su comercio -específicamente, a partir del año 2001, con la inclusión de China a la Organización Mundial de Comercio (OMC)- exteriorizada a través de la disminución de aranceles, la reestructuración de las empresas, la creación de políticas para disminuir el desempleo, el desarrollo de zonas económicas libres para el comercio exterior, la aperturas de zonas financieras, el aumento de las exportaciones, entre otras (Chen \& Lombaerde, 2013).

Dentro de este panorama, en el tema de café, particularmente, China tam- 
bién ha presentado una transformación positiva. A pesar de ser una nación especialmente conocida por el consumo de té, las importaciones de café y su consumo en general, se han incrementado sorpresivamente en los últimos diez años (El Colombiano, s.f.).

Como se muestra en la gráfica siguiente (3), la demanda del café presenta aumentos acelerados. Por ejemplo, entre 2001 y 2006, el mercado del café duplicó su tamaño y de acuerdo a los pronósticos realizados por Euromonitor, se espera que el mercado tenga un crecimiento promedio anual de $7,8 \%$ entre el 2011 y 2016 (Euromonitor, 2012).

Gráfico 3. Crecimiento de las importaciones de Café de China (2001 - 2013) (millones de dólares)

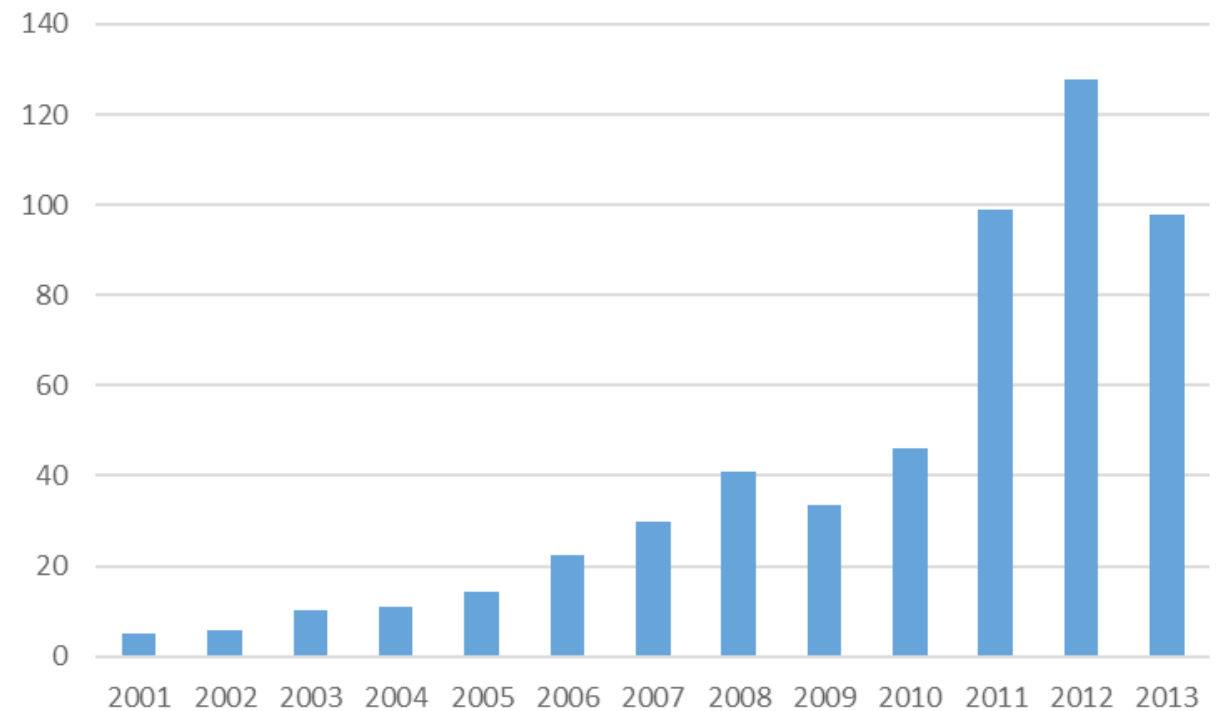

Fuente: Elaborado por el Semillero de Estudios Asia Pacífico con datos tomados del International Trade Center, 2013.

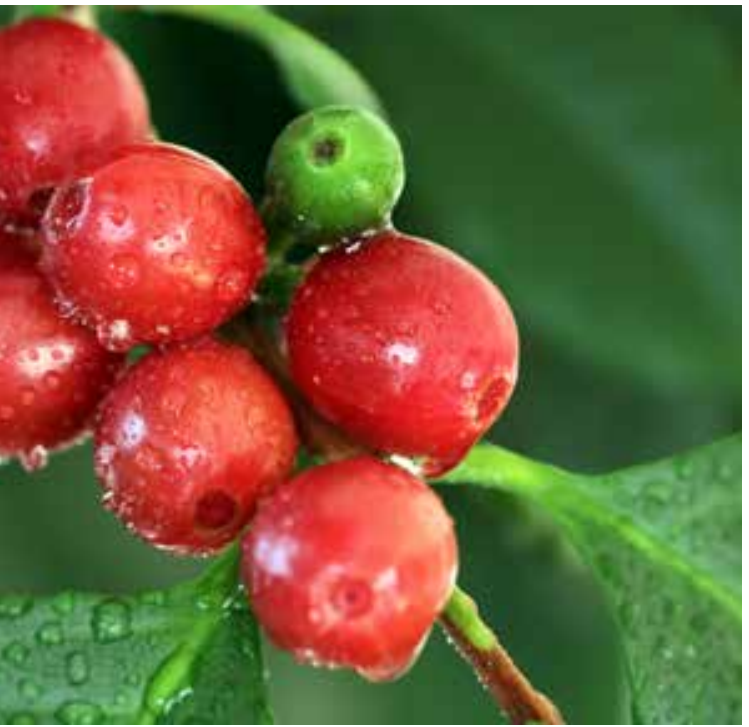

Aunque por el momento el mercado de café, se encuentra limitado por varios factores como las barreras comerciales, los costos de producción y la tradición cultural por el té; se espera que a mediano plazo, este producto conquiste tanto al consumidor chino como a otros subsectores en el sector industrial y comercial. Desde hace un par de años, la demanda del café ha aumentado constantemente, en particular en las ciudades más desarrolladas y con crecimiento económico elevado (Café de Colombia, 2012). Es por esto que desde el año 2011, el café ha sido un producto protagonista en las importaciones que China realiza de Colombia, convirtiéndolo, según Procolombia, ${ }^{1}$ en uno de los 16 productos con alto potencial para ingresar en el mercado chino (Centro de Comercio Internacional, 2011).

En la actualidad, las exportaciones de café desde Colombia hacia China están compuestas principalmente por café sin tostar y sin descafeinar, pues la demanda está especialmente orientada al café verde identificado con la marca del país (Café de Colombia, s.f.). Esto es muestra de que la industria colombiana aún sigue en la primera parte de la cadena productiva, vendiendo café verde con muy poco valor agregado, desaprovechando oportunidades y ventajas que tiene este mercado, además de múltiples nichos inexplorados de los que se pueden obtener grandes beneficios (Café de Colombia, 2012).

\footnotetext{
1 Procolombia, era antiguamente llamado Proexport.
} 
Gráfico 4. Exportaciones de café sin tostar desde Colombia a China (miles de dólares)

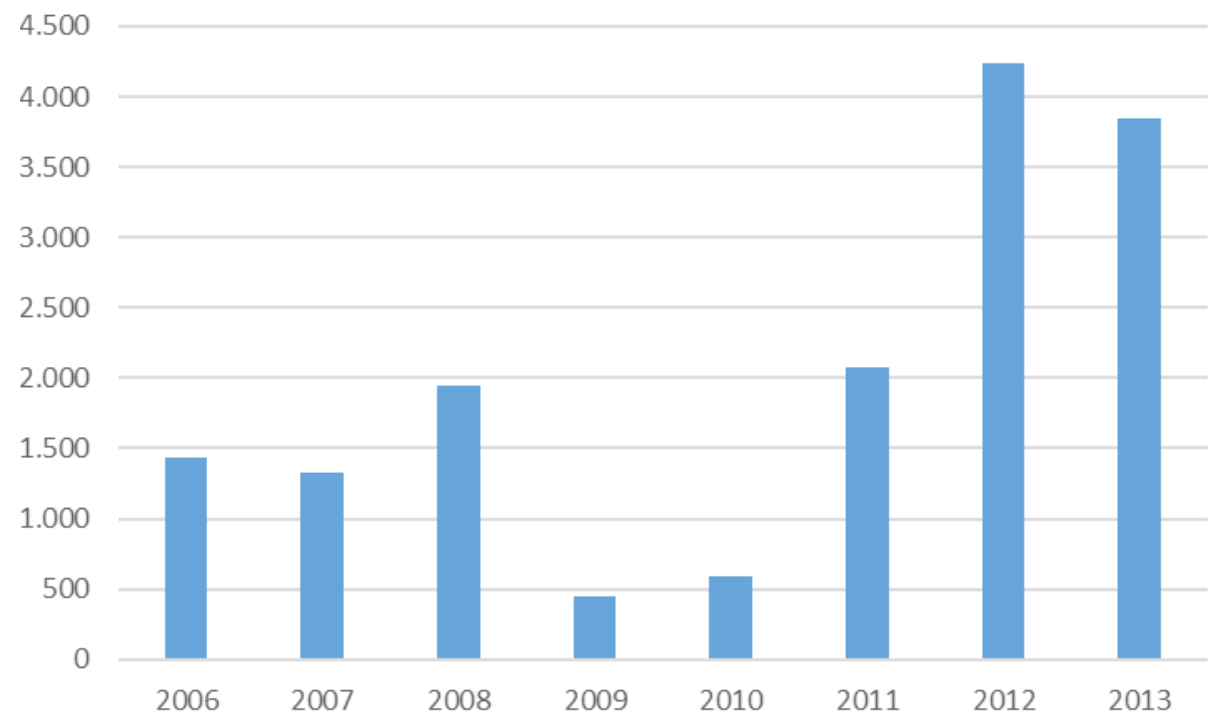

Fuente: Elaborado por el Semillero de Estudios Asia Pacífico con datos tomados del International Trade Center, 2013.

\section{MERCADO DE BEBIDAS CALIENTES EN CHINA}

Mercado, segmentación y tendencias de consumo de bebidas calientes en China

El mercado de las bebidas calientes en China ha registrado una dinámica de crecimiento constante y fuerte, que no se ha visto afectada por la reciente crisis económica que ha golpeado a varias industrias y mercados a nivel mundial.

Al cierre del año 2012, este mercado alcanzó un volumen de 666,8 millones de $\mathrm{kg}$, correspondiente a un valor de US\$13.300 millones, cifra que representa el $42,5 \%$ del valor de mercado total de la industria de bebidas calientes en Asia Pacífico. Comparativamente, para este mismo año los mercados japonés e indio registraron un valor de US\$5.300 millones y US\$3.400 millones respectivamente. Para el periodo 2008-2012, el valor del mercado de bebidas calientes en China registró una tasa de crecimiento anual compuesto (TCAC) de 6,2\%, frente a un incremento del 1,2\% para el mercado japonés y del 11,4\% para el mercado indio. Para finales del 2017, se pronostica que el mercado chino de bebidas calientes alcance un volumen de 780 millones de $\mathrm{kg}$, lo que equivale a un valor de US\$17.100 millones, lo cual correspondería a una TCAC de 3,2\% y de 5,2\% respectivamente para el periodo 2012-2017 (MarketLine, 2013). 
Tabla 2. Comportamiento del mercado de bebidas calientes en China y su dimensión frente a otros países asiáticos

\begin{tabular}{|c|l|l|l|l|l|l|l|l|}
\hline \multirow{2}{*}{ Países } & $\begin{array}{c}\text { Incremento de la TCAC } \\
2008 \text { - } 2012\end{array}$ & \multicolumn{2}{c|}{ Valores $\mathbf{2 0 1 2}$} & \multicolumn{3}{c|}{ Estimado $2012-2017$} \\
\cline { 2 - 10 } & En dólares & En volumen & $\begin{array}{l}\text { Millones de } \\
\text { dólares }\end{array}$ & $\begin{array}{l}\text { Millones de } \\
\mathrm{kg}\end{array}$ & $\begin{array}{l}\text { Millones de } \\
\text { dólares }\end{array}$ & $\begin{array}{l}\text { Incremento de la } \\
\text { TCAC en dólares }\end{array}$ & Millones de kg & $\begin{array}{l}\text { Incremento de la } \\
\text { TCAC en volumen }\end{array}$ \\
\hline China & $6,2 \%$ & $2,4 \%$ & 13.300 & 666.8 & 17.100 & $5,2 \%$ & 780 & $3,2 \%$ \\
\hline Japón & $1,2 \%$ & n.d. & 5.300 & n.d. & 5.700 & $1,20 \%$ & n.d. & n.d. \\
\hline India & $11,4 \%$ & n.d. & 3.400 & n.d. & 5.200 & $9,20 \%$ & n.d. & n.d. \\
\hline
\end{tabular}

Fuente: Datos tomados de MarketLine, 2013.

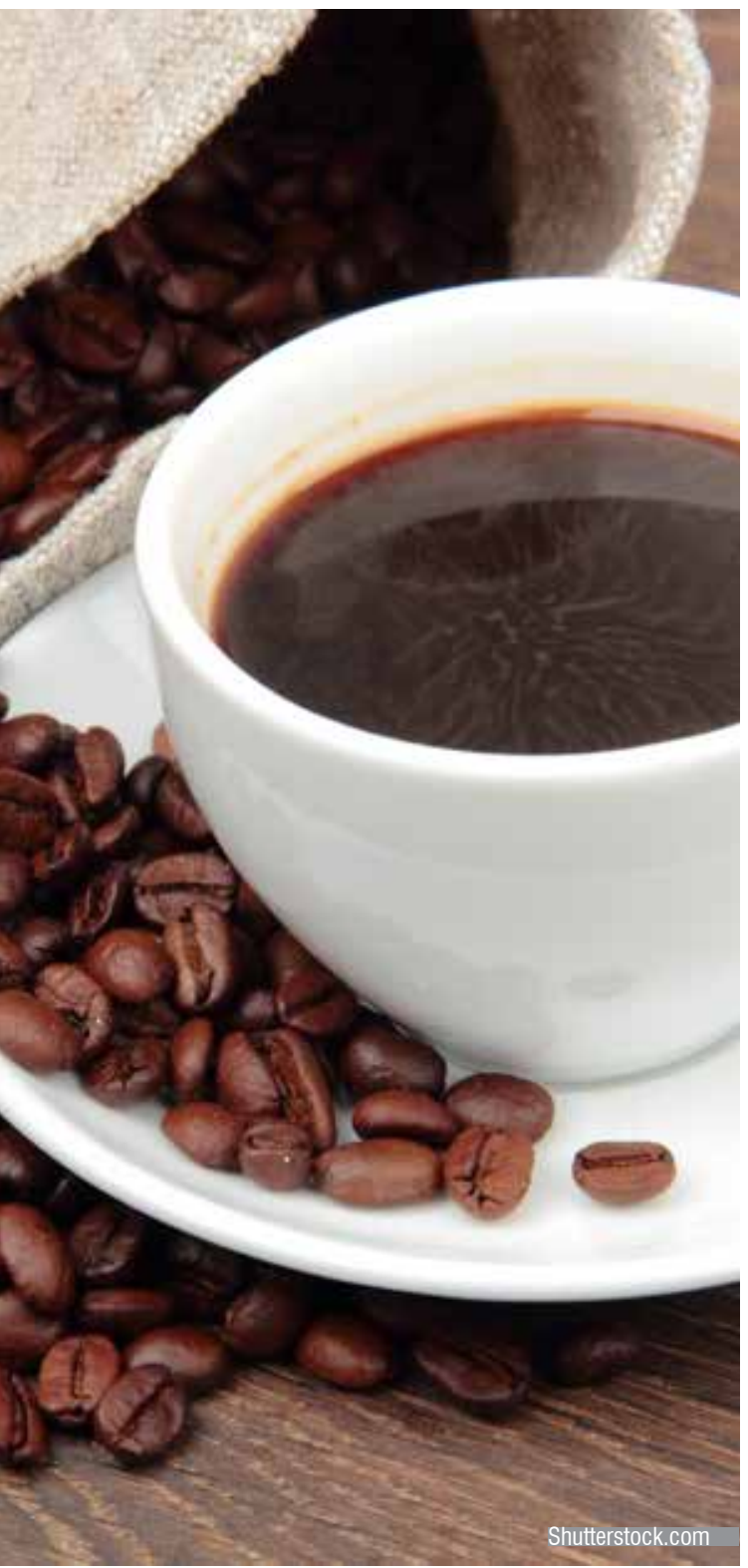

Las cifras anteriores indican que China ocupa un lugar preponderante en los mercados de bebidas calientes de Asia Pacífico, con una segmentación de mercado que para 2012 registraba una participación dominante del té con el 95,4\% -es decir US\$12.700 millones del valor total del mercado-, frente a un 3,3\% -equivalente a US\$443 millones- del café y un 1,3\% - US\$157 millonesde otras bebidas (MarketLine, 2013).

Tabla 3. Segmentación del mercado de bebidas calientes en China en el 2012

\begin{tabular}{|c|c|c|}
\hline Segmento & Millones de dólares & $\%$ \\
\hline Té & 12.700 & $95,4 \%$ \\
\hline Café & 443 & $3,3 \%$ \\
\hline $\begin{array}{c}\text { Otras bebidas } \\
\text { calientes }\end{array}$ & 157 & $1,3 \%$ \\
\hline TOTAL & 13.300 & $100 \%$ \\
\hline
\end{tabular}

Fuente: Datos tomados de MarketLine, 2013.

La población actual de China -1.357 millones- consume tan solo cuatro millones de tazas de café anuales. Este consumo se realiza principalmente por la poblacion de clase media con capacidad adquisitiva, que son aproximadamente 157 millones de personas, y se espera que para 2020 aumente a 500 millones (Duarte, 2013).

\section{La industria del té en China}

China es el principal productor de té en el mundo. En 2012 registró 2,11 millones de hectáreas de cultivos, una producción de 1,62 millones toneladas, es decir el 36,8\% del total mundial; y un consumo interno de un 1,23 millones de toneladas, equivalente al 30\% del consumo a nivel global (Firsd Tea, 2013). Por otro lado, durante el período 2012-2013, se produjeron en la provincia de Yunnan en China, entre 36.000 y 45.000 toneladas de grano de café (Organización Internacional del Café , 2013; Feliciano, 2013).

A pesar de la tan arraigada cultura del té en China, las tendencias de consumo de bebidas calientes en el país, han permitido el ingreso al mercado de otras alternativas como el café. Según el estudio Hot Drinks in China publicado por MarketLine (2013), "el precio del té y el café están determinados por su calidad, suministro y demanda. Los vendedores de café han venido trabajando en la transformación de China, de ser la patria del té a convertirse en una nación de café" (MarketLine, 2013). 


\section{Producción e industria cafetera en China}

"China, tierra natal del té, donde la tradición por esta bebida ha llevado a elaborar cientos de famosos tés durante milenios, nos sorprende al interesarse en los últimos años en la producción de café" (Infusionistas, 2011). China no es un país conocido por su producción cafetera, ésta ha estado asociada generalmente a países latinoamericanos, africanos o del Sureste Asiático (Roldán-Pérez, Gonzalez- Perez, Thu Huong, \& Ngoc Tien, 2008). Sin embargo, esta industria se ha desarrollado, principalmente a través del cultivo del grano en tres provincias ubicadas al Sur y Sureste del país: Yunna, Hainan y Fujian. En la provincia de Yunnan se produce aproximadamente el 98\% de la producción total de café en China, siendo sus mayores zonas productoras Kunming, Simao, Ruili y Baoshan (véase imagen 1) (Organización Internacional del Café, 2013). Esta concentración, se debe a que Yunnan es una de las provincias más diversas en términos geográficos, con una gran abundancia en recursos naturales, especialmente hídricos y con características topográficas aptas para el cultivo del café. Cabe resaltar que el tipo de café que Yunnan produce es en su totalidad arábica, al igual que en Colombia, mientras que en las otras dos provincias, se trata de café robusta (International Trade Centre, 2010).

La producción de China ha incrementado a un promedio anual del 15,1\% de acuerdo a cifras de la Organización Internacional de Café (2013) (véase gráfico 5). Es importante aclarar que una gran cantidad (entre el $80 \%$ y $90 \%$ ) del café producido en China tiene destinos internacionales, siendo vendido en su mayoría en forma de café verde a través de distribuidores extranjeros (International Trade Centre, 2010). Entre sus principales clientes en el 2012 se encontraban Alemania y Japón, países posicionados entre los cinco principales importadores de café a nivel mundial (Roldán-Pérez et al, 2008; Organización Internacional del Café, 2013).

\section{Imagen 1. Principales zonas productoras de café en China}

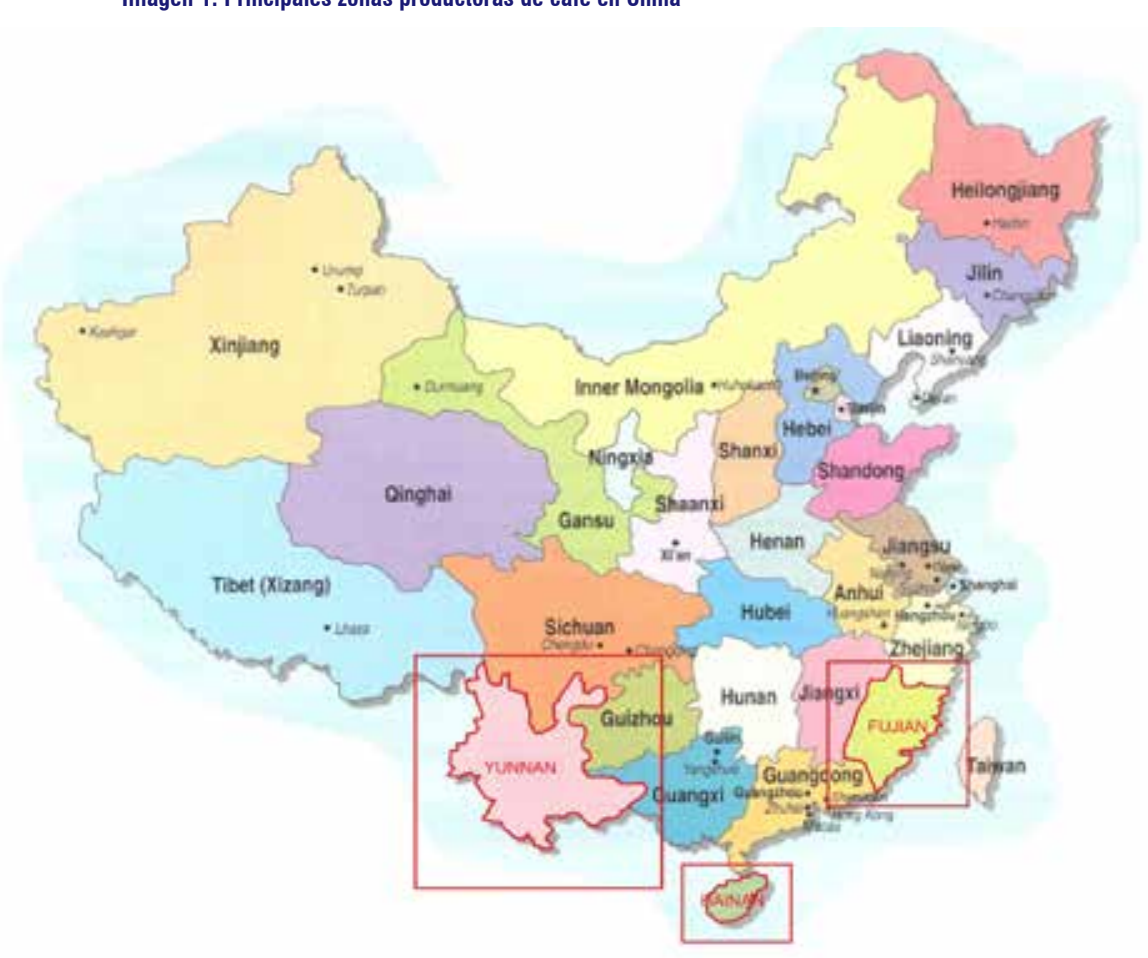

Fuente: Organización Internacional del Café , 2013 
Gráfico 5. Producción de Café en China

Producción de café en China

(Años civiles 1998 a 2012)

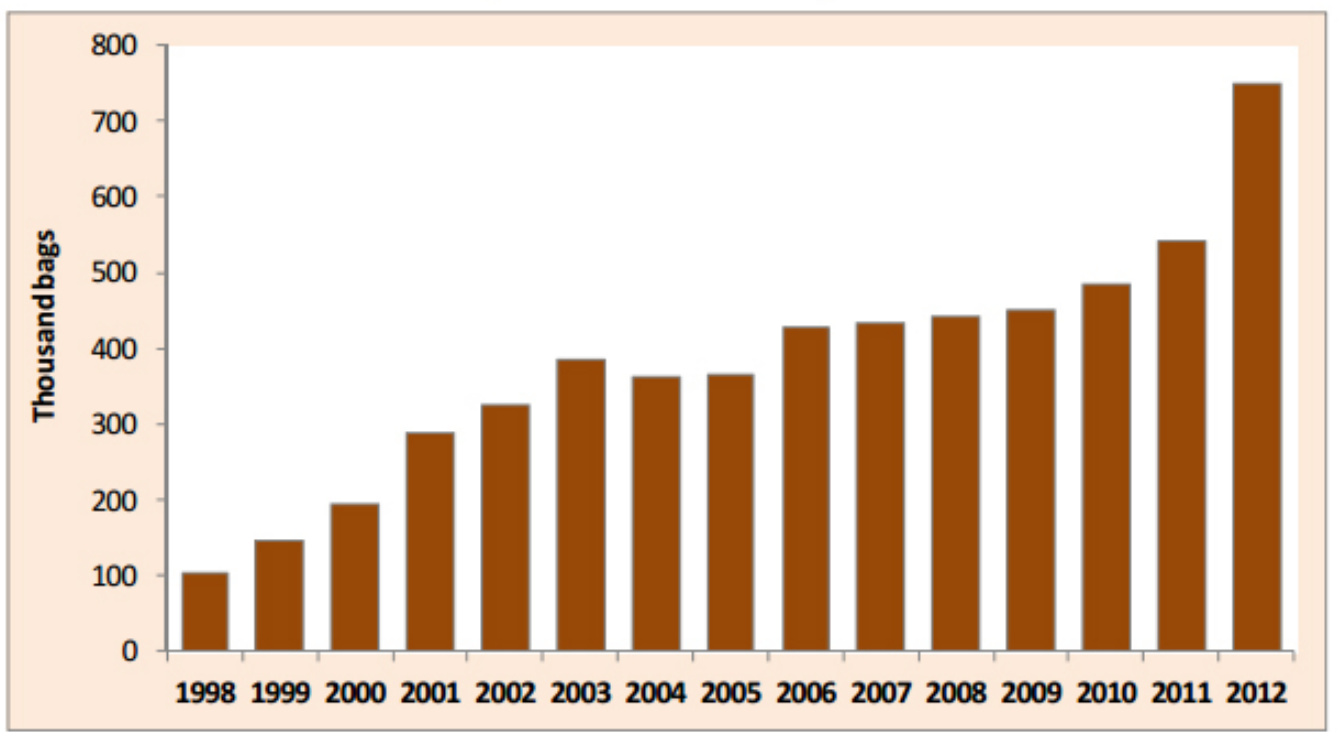

Fuente: Elaborado por el Semillero de Estudios Asia Pacífico con datos tomados de la Organización Internacional del Café, 2013.

El interés de China por incursionar no sólo en el consumo de esta bebida típica de occidente, sino también en su producción, se intensificó durante los años 80, cuando en el país comenzaba la apertura internacional (Infusionistas, 2011). Este naciente interés se vio reflejado tanto en acciones privadas como públicas; por parte del Estado, se llevó a cabo un programa en conjunto con el Programa de las Naciones Unidas Para el Desarrollo (UNDP), en donde se promovió la producción de café (Organización Internacional del Café, 2013). Luego, empresas privadas también se vieron interesadas en catapultar la industria del café en el país asiático, especialmente en la provincia de Yunnan. Dentro de estos casos puede mencionarse a Nestlé durante los años 80, y a Starbucks que dio su primer paso en el 2009 (Barlow, 2013). Por esto, y debido a políticas gubernamentales, los cultivos de café en China cuentan con un porcentaje de propiedad pública y uno de propiedad privada (Espresso \& Coffee Guide, s.f.).

Desde 1998, se ha dado un crecimiento de la producción en China, gracias a los incentivos del gobierno local y a los beneficios económicos que el café inherentemente trae para los caficultores, pues ellos obtienen mayor utilidad por la siembra de café que por la del té debido a que en los últimos años la demanda ha superadola oferta, y consecuentemente el precio del grano de café ha aumentado (Liu B. , 2012; De Smet, 2013). Lo anterior se hizo evidente en el período comprendido entre 2008 y 2011 cuando el precio del grano se duplicó, pasando de \$16 yuanes el kilo en 2008 a \$30 yuanes en 2011, es decir US\$2,6 y US\$4,8, respectivamente (Gibson, 2013).

Con respecto a la calidad del café que allí se cultiva las opiniones varían. A pesar de tratarse de café arábigo, que como categoría en general es de mejor calidad que el tipo robusta, algunas personas como el vicepresidente de la Asociación de Café de Yunnan, Dong Zhihua (2013), piensa que aún 


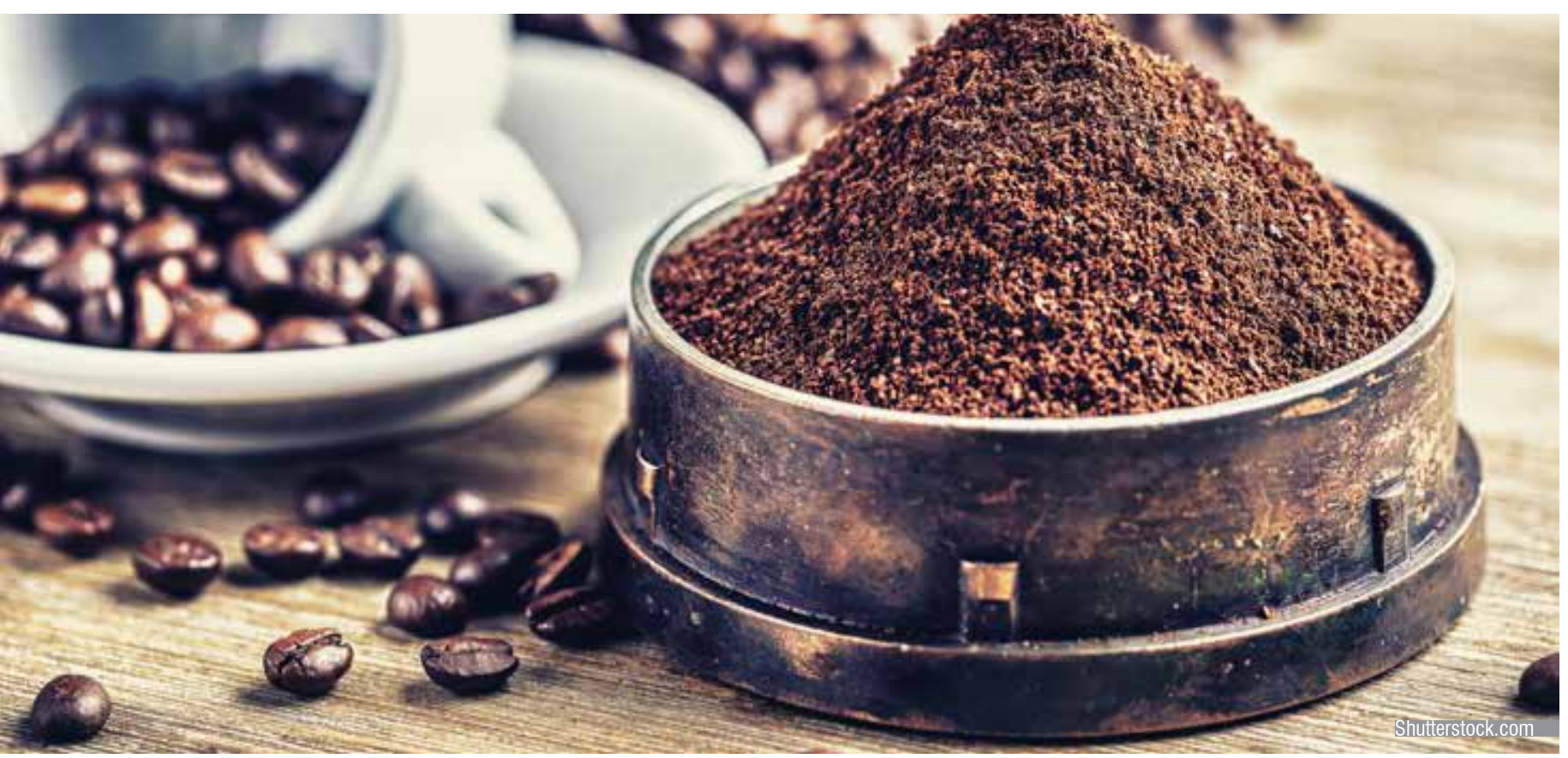

debe mejorar. Lo anterior se ve reflejado en la falta de reconocimiento de la variedad de café allí sembrado, que no cuenta con los estándares de los denominados cafés especiales y que es en parte causado tanto por la falta de experiencia en el cultivo del grano como por la falta de infraestructura (Kwong, 2013; Wan, 2013; Roast Magazine, 2013).

Con el fin de evidenciar el mencionado crecimiento en la producción de café en China, se expondrá el caso de tres empresas, dos nacionales y una internacional, que en ese país se dedican exitosamente a la producción de café, fortalecida por el surgimiento de una industria de café, basada en el cultivo del mismo en la provincia de Yunnan. Esas empresas son:

- Hogood Coffee (Dehong Hogood Coffee Co. Ltd.): Hogood Coffee, originaria de la provincia de Yunnan, fue creada en el año 2007 y desde entonces se ha constituido como una de las empresas líderes en la plantación y tostión de café de la provincia. Del café arábigo producido, la empresa comercializa café verde, tostado e instantáneo, que en su mayoría es exportado a Europa y Corea del Sur.

- ManLaoRiver: Esta es una de las mayores empresas cafeteras de la provincia de Yunnan. ManLaoRiver surge de un proyecto realizado por el gobierno de Yunnan y una empresa de alimentos naturales, en donde se buscaba aliviar la pobreza que sufrían las minorías étnicas de la comunidad y proteger el medio ambiente.

- Nestlé (Nescafé): la muy reconocida compañía suiza de productos alimenticios llegó a China a finales de los años 80 con el objetivo de impulsar la producción de café principalmente en la región de Yunnan. A pesar de los casos exitosos de empresas chinas e internacionales de café, los esfuerzos para incentivar e incrementar la producción del grano son aún incipientes, por ello el reconocimiento y posicionamiento de su café aún no es tan sólido como el de otros países de tradición cafetera y todavía enfrenta desafíos en términos de la calidad de su oferta.

En su mayoría el café producido en Yunnan es muy costoso para los consumidores chinos, y por esa razón una gran proporción de éste es 


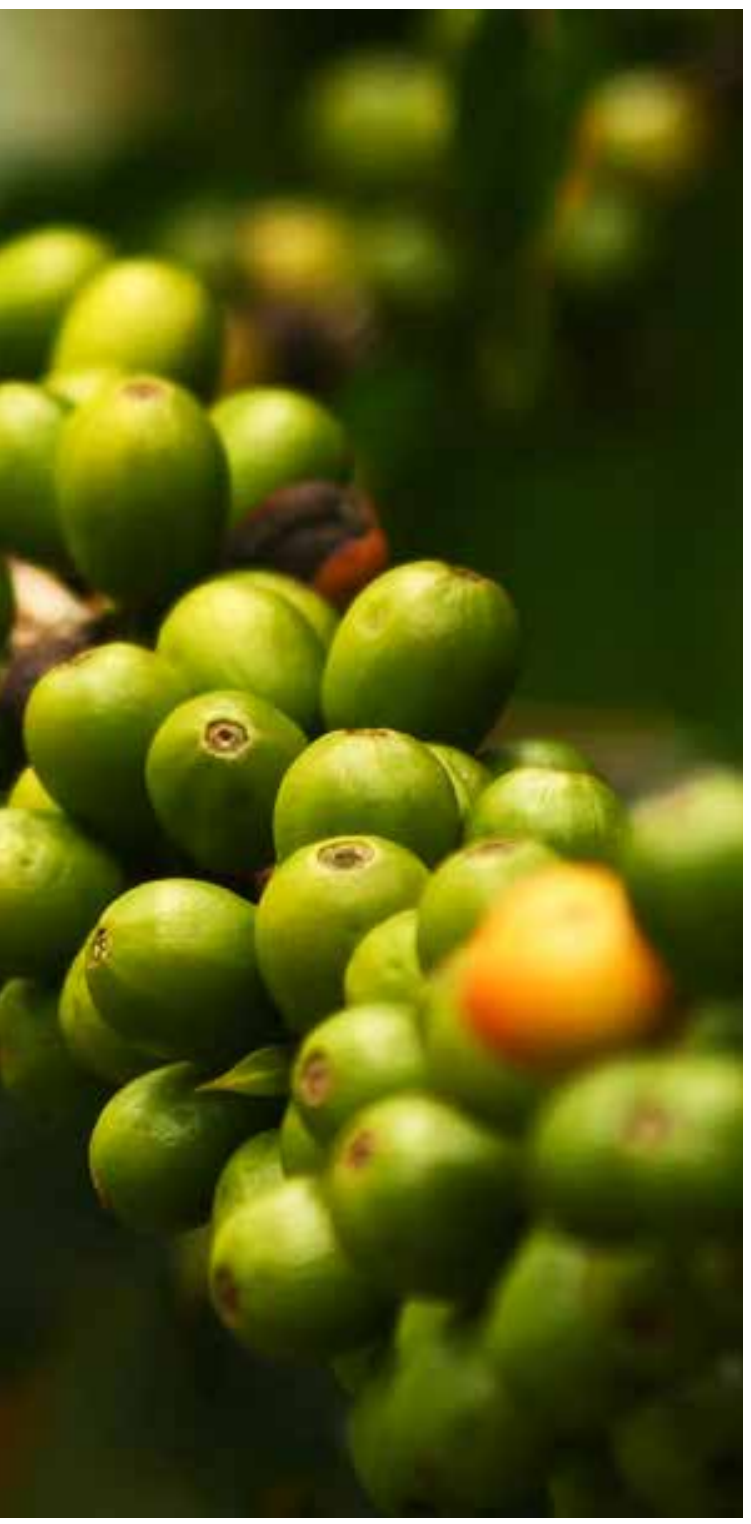

comercializado en el exterior. Además, no cuenta con las características óptimas para ser considerado un café especial. Estos desafíos y obstáculos que enfrenta la industria china de café representan para los caficultores colombianos una oportunidad de posicionarse en ese mercado, gracias a fortalezas como la reconocida calidad de su producto, el ser considerados como productores de cafés especiales, y su experiencia histórica en la industria.

\section{Importaciones de Café en China}

Aunque en China el consumo de café ha venido creciendo y se pronostica que lo siga haciendo, el país aún no se cataloga entre los mayores importadores de café en el mundo, a pesar del crecimiento que han presentado las mismas en los últimos años (Euromonitor, 2014). En 1998 las importaciones de café en China correspondían aproximadamente a 16.241 toneladas; según la Organización Internacional del Café (2013) en el período correspondiente entre 1998 y 2012, las importaciones totales de café en China crecieron en promedio hasta 37.312 toneladas, logrando un cambio significativo. Posteriormente, las mismas alcanzaron un total de 98.000 toneladas durante 2012; es decir, seis veces la cantidad importada al comienzo del período mencionado -un crecimiento aproximado del 13,7\% anual-.

Respecto al tipo de café importado, el café verde es el principal producto. En el período 1998-2012, constituyó en promedio el 70\% del total de café importado anualmente. Las importaciones de café verde llegaron a un total de casi 69.000 toneladas en el año 2012, representando el 70,5\% del total de importaciones de café en ese mismo año (Organización Internacional del Café , 2013).

En este orden de ideas, el peso de este tipo de café dentro de la balanza importadora es representativo, sin dejar de lado el papel que han jugado los otros tipos de café como el soluble y el tostado, los cuales contaban con una mayor representación dentro de las importaciones de café a finales de los 90. Existen diversos factores que explican el cambio en la composición de las importaciones de café:

Desarrollo de la industria local de elaboración: en China algunos importadores también cumplen el rol de tostadores y/o comercializadores de café, realizando incluso sus propias mezclas para adaptarse a las preferencias del consumidor. Por ello prevalece la importación del café verde, el cual es una materia prima óptima para la elaboración de productos y también el motivo por el cual el consumo interno de café puro es escaso (Arias-Leitón \& Tristán, 2008). Lo que busca desarrollar la industria del café en China es un café más económico y menos ácido, a pesar de que demanda de cafés especiales y de origen ha ido en aumento, tendencia que se ha presentado gracias a la occidentalización de los gustos (Euromonitor, 2014).

La presencia de empresas multinacionales: empresas de carácter internacional han establecido plantas de producción en China, entre ellas la principal es Nestlé; que con una cobertura de 75\% del mercado realiza la transformación del producto a base de granos tanto nacionales como internacionales (International Trade Centre, 2010).

Mayor demanda de cafés especiales y cafés de origen: a medida que la tendencia de occidentalización avanza, los consumidores comienzan a interesarse por características como el origen, sabor, aroma, métodos de producción, tostión y otras especialidades del café (Euromonitor, 2014). Esta tendencia se presenta en su mayoría para el café verde y se espera que también se extienda hasta los solubles instantáneos en el futuro.

Por ello, en la condición de consumidor de café en su mayoría importado, -y predominantemente verde- China cuenta con socios comerciales que han abastecido su mercado desde hace algunos años. Los principales origenes 
del café importado por China en 2012 son: Vietnam, de donde provino el 50,5\%; Indonesia con el 15,8\%; seguidos por Malasia con el 6.1\%; Brasil origen del 5,6\%; Estados Unidos con un 5,5\% y finalmente Colombia con el 2,3\%. Estos seis países han sido los proveedores principales para China desde el año 1998 -cambiando de posición en el transcurso de los años- (Organización Internacional del Café , 2013).

Si bien, en un contexto general la cifra es incipiente, las exportaciones de café colombiano hacia China han tenido un crecimiento importante impulsado por una demanda cada vez mayor, y por un interés en productos de calidad y origen. Lo anterior se evidencia especialmente en el período entre 2001 y 2005, en donde se presentó un crecimiento de 1,5\%, en las exportaciones de café desde Colombia hacia China, cuando el mercado era aún incipiente (Centro de Comercio Internacional, 2013).

El comportamiento de las exportaciones de café colombiano hacia China en los últimos tres años ha sido diferente. En el año 2011, las exportaciones correspondían a US\$2,07 millones. Este valor se duplicó en 2012, en donde las exprotaciones totalizaron US\$4,241 millones (Proexport, 2014). Sin embargo, para el 2013 se registró una caída en el valor de las exportaciones pasando a ser de US\$3.840 millones. Es posible que este fenómeno haya ocurrido debido al fuerte verano que se presentó ese año y que incrementó el consumo de bebidas frías, afectando severamente las ventas de café a nivel general. Finalmente para el mes de agosto del año 2014 se presentó una recuperación, con exportaciones de US\$4.839 millones, lo que señala un aumento importante y alentador (Euromonitor, 2014).

Con estas cifras de crecimiento, es evidente la oportunidad que tiene la industria del café colombiano en el gigante asiático. Es por ello que resulta importante analizar las barreras tanto arancelarias como no arancelarias para la entrada de este producto a China. De acuerdo a estadísticas provistas por el Centro de Comercio Internacional a través de Trade Map (2013), los aranceles aplicados a los diferentes tipos de café son: para el no tostado o verde un arancel del $8 \%$, el tostado de $15 \%$ y finalmente las cáscaras y las pieles del café tienen el 20\%. Adicionalmente, para ingresar mercancías a China, se debe pagar un Impuesto al Valor Agregado (IVA) del 17\% (Proexport, 2008). Lo anterior sumado a diversos requisitos no arancelarios, como lo son aquellos de etiquetado; sanitarios y fitosanitarios; y la obtención de licencias necesarias para la importación de café que se han convertido en un importante requisito para la comercialización de la mayoría de productos hacia China (Organización Mundial del Comercio, 2014; Legiscomex, 2010).

Cabe anotar que no habria dificultad en atender un incremento en la demanda de café colombiano en China pues, de acuerdo con la Federación Nacional de Cafeteros, en el año 2020 se espera que la producción supere los 18 millones de sacos (Federación Nacional de Cafeteros de Colombia, 2013).

\section{El consumo de café en China y sus principales tendencias}

La transformación y el crecimiento económico que se ha experimentado en China en las últimas tres décadas han permitido cambios en tendencias del consumidor chino que se asimilan a patrones de consumo occidental. En general algunas actividades -entre las que se incluye el consumo de caféson vistas como una muestra de sofisticación y estatus. Los baristas, catadores y grandes consumidores de café forman una corriente cultural alrededor del mismo que incita a sus consumidores a preferir la más alta calidad de café excelso. Esta percepción ayuda a comprender las motivaciones del consumidor chino para probar una bebida como el café.

Se describen a continuación algunos factores que inciden en el comportamiento del consumidor chino en general, como el incremento del poder ad- 


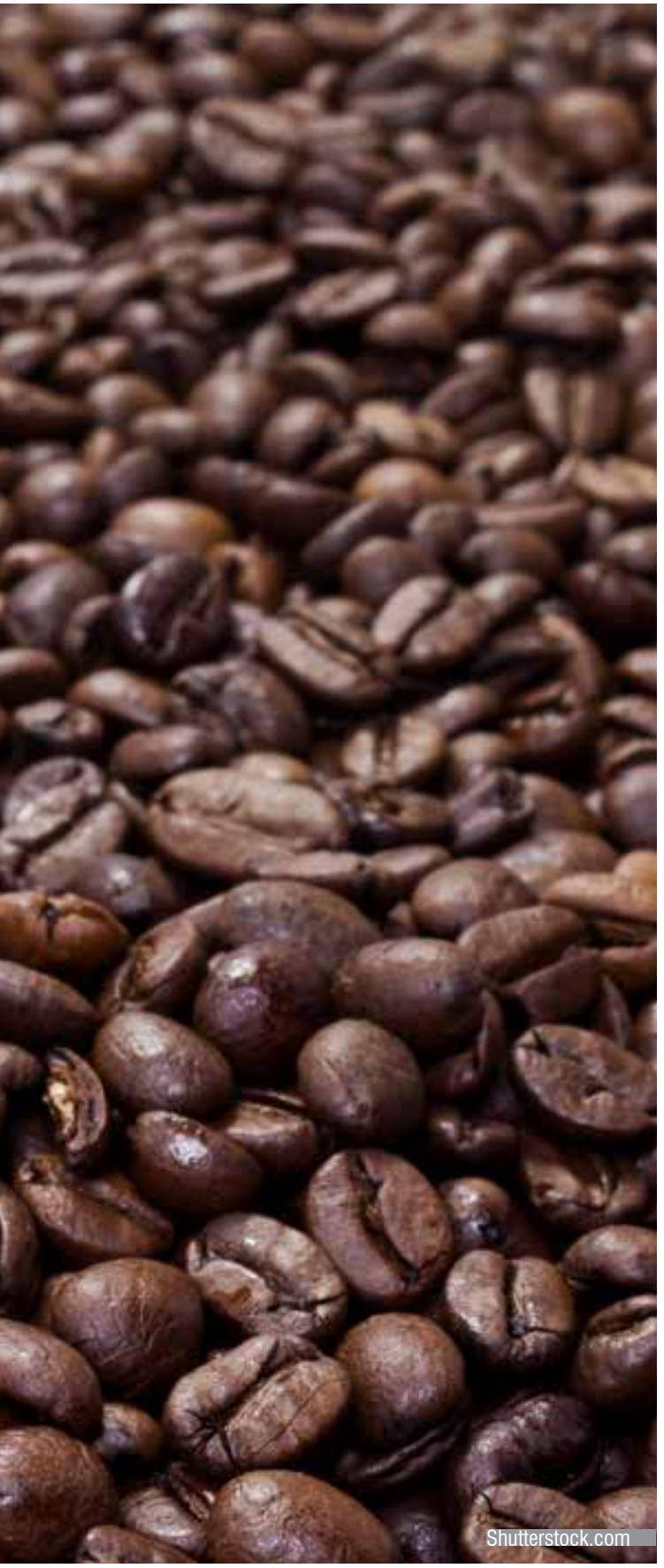

quisitivo; y en particular, los elementos que influyen en las preferencias del consumidor de café.

\section{Crecimiento de la clase media}

El incremento del poder adquisitivo de la clase media china y el crecimiento de la misma, ha llevado a que el consumidor demande productos similares a los occidentales, principalmente confitería y bebidas no alcohólicas (Proexport, 2012). La clase media en China se estima hoy en 157 millones de habitantes y para 2020, sumaría alrededor de 500 millones, lo que convertiría al país en el principal mercado mundial (Duarte, 2013).

\section{Incremento en los ingresos}

De acuerdo con Ovalle (2013), los pronósticos indican que el PIB de China seguirá incrementando y este crecimiento surgirá por medio de un ciclo donde el consumo aumentará, entre otros factores, por la tendencia a una rápida urbanización y por las políticas de gobierno que lo incentivarán (Ovalle, 2013). De acuerdo con la firma consultora McKinsey (2012), los tipos de consumidor urbano en China se pueden clasificar en cuatro grupos según su salario, el primero (bajos ingresos) compuesto por aquellos que devengan un salario anual menor a US\$6.000 -equivalente al 10\% de la población para el año 2010-; el segundo grupo (value) está compuesto por quienes devengan entre US\$6.000 y US\$16.000, que corresponde el 82\% de la población para el mismo año; un tercer grupo (clase media) que devenga entre US\$16.000 y US\$34.000 (6\% de la población para el año 2010); y un cuarto grupo, que representa el $2 \%$ de la población, donde se encuentran los descritos como "adinerados" con un ingreso anual superior o igual a US\$34.000. El siguiente gráfico refleja la clasificación del consumidor en áreas urbanas según su ingreso y modela la tendencia de los grupos hasta el año 2020.

Gráfico 6. Número de hogares urbanos en China e Ingreso anual (Millones de hogares, porcentaje)
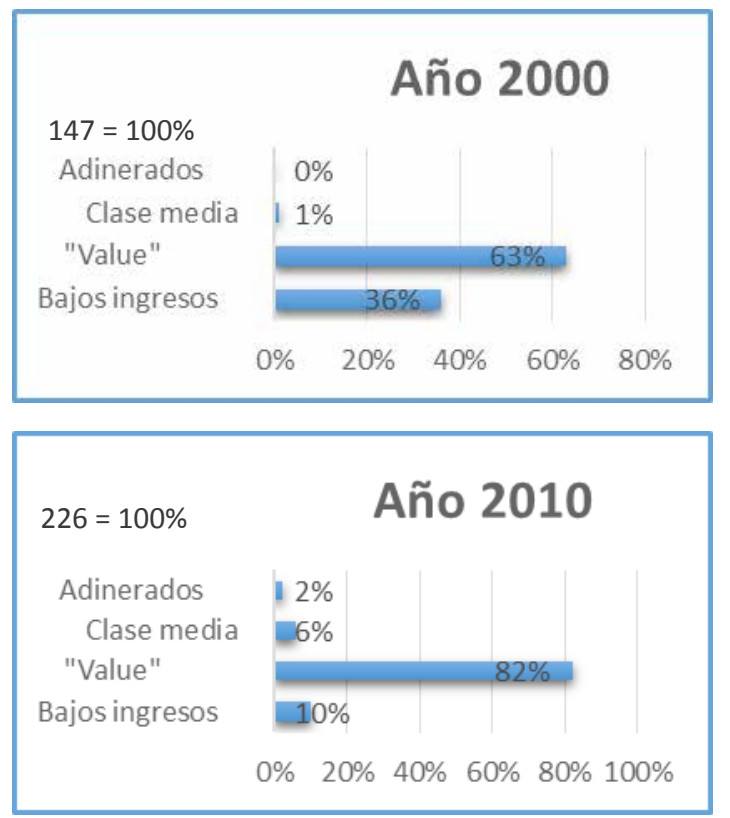

Adinerados: Hogares con ingresos anuales superiores a US\$34.000.

Clase media: Hogares con ingresos anuales entre US\$ 6.000 y US $\$ 34.000$.

"Value": Hogares con ingresos anuales entre US\$ 6.000 y US $\$ 16.000$.

Bajos ingresos: Hogares con ingresos anuales inferiores a USD6.000. 


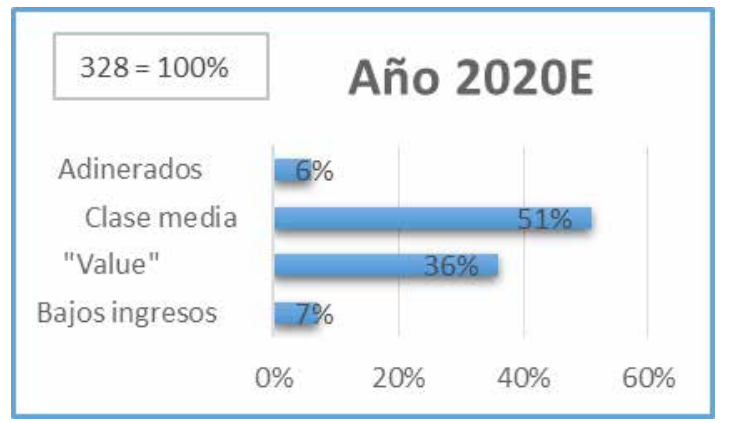

Fuente: Elaboración del Semillero de Estudios Asia Pacífico con datos de McKinsey Insights China (Marzo de 2012).

\section{Región geográfica}

En la actualidad, el consumo de café en China se concentra en las ciudades más importante del Este y el Sur de China, específicamente Beijing, Shanghai y Guangzhou además de las regiones administrativas especiales de Hong Kong y Macao.

\section{El lugar de consumo}

Otro aspecto a tener en cuenta son las formas de consumo de café en China que están ligadas al lugar de consumo, pues, no es un producto de la canasta familiar. Por lo tanto "la actividad del consumo de café se lleva a cabo por fuera del hogar principalmente en cafeterías, cafés independientes y restaurantes de comida rápida" (Arias \& Tristán, 2008).

De acuerdo con Liu (2013), el consumo de café está estrechamente ligado con un nuevo estilo de vida, en el cual cobra importancia los establecimientos de café como lugares, fuera de casa y del trabajo, destinados a la socialización y el esparcimiento (Liu A., 2013). El concepto de café para llevar aún no es fuerte en el mercado chino, esto puede ser debido a que el consumo de café es más una actividad social. Sin embargo, se pueden encontrar presentaciones enlatadas de café listo para ser consumido.

\section{Potenciales consumidores}

El informe de Arias y Tristán (2008) clasifica el consumidor, chino en tres grupos principales:

Jóvenes adultos: el segmento de la población considerada como jóvenes adultos (entre 18 y 29 años de edad) lidera algunas de las nuevas tendencias de consumo dentro de las que se encuentra el consumo de café. Estos consumidores le dan gran importancia a los conceptos de estilo de vida y marcas, y al mismo tiempo se encuentran dentro de los segmentos con mayores ingresos disponibles (Euromonitor, 2013).

El tamaño de este grupo se ha mantenido relativamente estable durante la última década y se estima que va a disminuir levemente hasta el 2015. A continuación se muestra una tabla en la cual se compara el tamaño de los diferentes segmentos de consumidores en China (según su edad) y su tendencia hasta el año 2015: 
Tabla 4. Distribución de la población china según grupos de edad (en millones)

\begin{tabular}{|c|c|c|c|c|c|c|}
\hline & $\mathbf{2 0 0 0}$ & $\mathbf{2 0 0 5}$ & $\mathbf{2 0 1 0}$ & $\mathbf{2 0 1 1}$ & $\mathbf{2 0 1 2}$ & $\mathbf{2 0 1 5}$ \\
\hline Bebes/infantes (edad 0-2) & 40.209 & 39.575 & 40.232 & 39.828 & 39.538 & 40.452 \\
\hline \hline Niños entre 3 y 8 años & 103.580 & 87.355 & 85.545 & 86.616 & 86.841 & 80.870 \\
\hline Niños entre 9 y 12 años & 100.620 & 73.597 & 60.805 & 58.166 & 56.759 & 58.252 \\
\hline Adolecentes (edad 13-17) & 111.974 & 118.041 & 84.832 & 80.359 & 79.549 & 74.146 \\
\hline Jóvenes adultos (edad 18-29) & 240.691 & 210.150 & 229.535 & 231.257 & 227.392 & 223.252 \\
\hline \hline adultos (edad 30-44) & 320.485 & 351.418 & 332.888 & 326.776 & 322.970 & 292.315 \\
\hline \hline Adultos mayores (edad 45-59) & 203.984 & 253.540 & 301.560 & 310.717 & 314.490 & 336.773 \\
\hline \hline Tercera edad ( 60+) & 136.317 & 166.203 & 199.104 & 207.192 & 219.555 & 257.854 \\
\hline \hline Población: Nacional & 1.257 .860 & 1.299 .880 & 1.334 .500 & 1.340 .910 & 1.347 .093 & 1.363 .912 \\
\hline Estimada al 1ero de enero & & & & & & \\
\hline Población edad 0-14: & 291.112 & 243.304 & 220.025 & 216.744 & 214.031 & 208.228 \\
\hline 1ero de enero & & & & & & \\
\hline Población edad 15-64: & 869.058 & 940.839 & 983.147 & 988.324 & 990.342 & \\
\hline 1ero de enero & & & & & & \\
\hline Población edad 65+: & 92.691 & 115.738 & 131.328 & 135.842 & 142.720 & 167.074 \\
\hline 1ero de enero & & & & & & \\
\hline
\end{tabular}

Fuente:Elaborado por el Semillero de Estudios Asia Pacífico con datos tomados de Euromonitor, 2013.

Extranjeros: grupo compuesto por turistas, trabajadores expatriados y viajeros de negocios. Este grupo influye en el incremento de la demanda de café por parte de canales institucionales (restaurantes y hoteles) y en la apertura de cadenas de cafeterías (Arias-Leitón \& Tristán, 2008).

Quienes retornan al país: este grupo está conformado por ciudadanos chinos que regresan a su país luego de haber vivido por un periodo en occidente. Estos ciudadanos traen consigo las prácticas de consumo que han adquirido en estos países, dentro de las que se destaca el consumo de café (Arias \& Tristán, 2008).

\section{Cómo se consume el café en China}

El consumidor chino de café generalmente desconoce la preparación y características distintivas de la bebida, tales como aroma, acidez, tipos, tuestes y verdaderos orígenes entre otros; es por esto que prevalece en el mercado el consumo de mezclas y café instantáneo (Arias \& Tristán, 2008). De acuerdo a la Asociación de Café de Beijing, la cultura del café ha venido incrementando su importancia dentro del segmento del café, el cual ha crecido cerca de un $15 \%$ en años recientes mientras que el promedio global es del 2\%. Empresas como Starbucks, Pacific Coffee e llly esperan un crecimiento sostenido principalmente en las ciudades emergentes chinas conocidas como tier 2 y tier $3 .{ }^{2}$ Andrea Illy, CEO de la compañía de café Illy, indicó en una entrevista para China Daily que espera que China se encuentre dentro de las cinco primeras naciones en cuanto al consumo de café para la próxima generación (Euromonitor, 2013).

2 La República Popular China puede ser dividida en Tiers. Según cita Adriana Roldán (2013) de Bolger (2012), esta clasificación considera cuatro aspectos fundamentales: tamaño de población, nivel de desarrollo, oferta de servicios, nivel de infraestructura y ambiente que las rodea. La Tier 1 alberga las metrópolis, las Tier 2 y 3 acogen las ciudades en desarrollo y la Tier 4 condados y prefecturas (Roldán, 2013). 


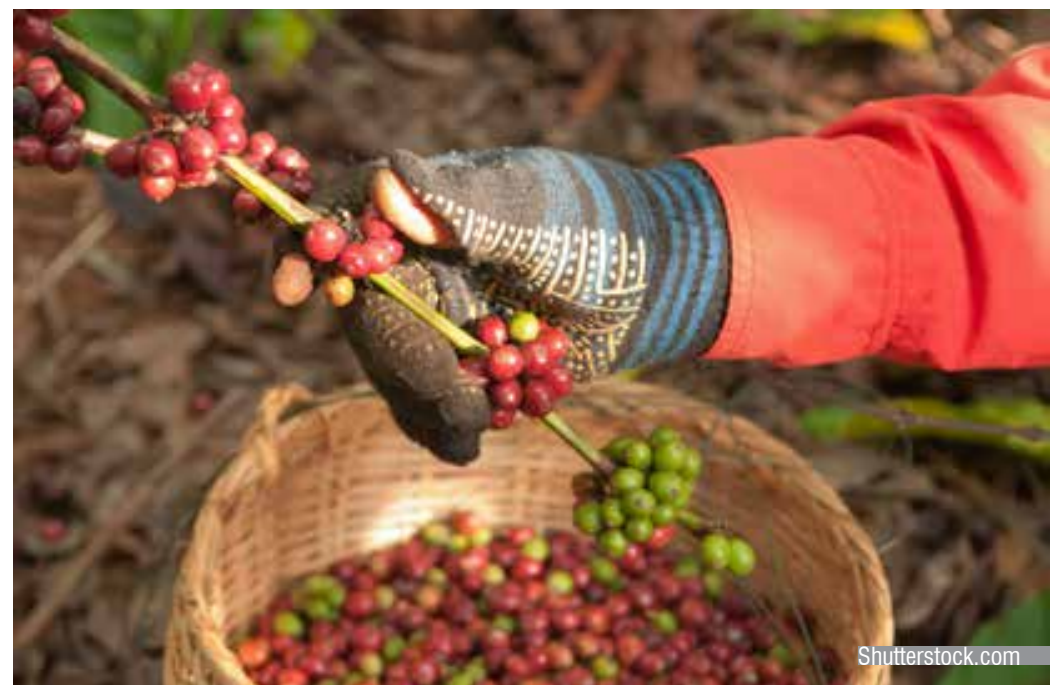

\section{Conclusiones}

China es hoy un actor global de suma importancia, que ofrece grandes oportunidades debido a las altas perspectivas de crecimiento y desarrollo de su mercado. Particularmente en el tema de café, China ha presentado una transformación muy positiva en donde la industria cafetera colombiana tiene posibilidades de participar.

El mercado de bebidas calientes en el país asiático ha registrado una dinámica de crecimiento constante y fuerte. A pesar de su arraigada cultura del té, las nuevas tendencias de consumo de bebidas calientes en el país, han permitido el ingreso al mercado de otras alternativas como el café. La inserción de una "cultura de café" en China es viable; las oportunidades están representadas por un mercado potencial en continua expansión de 1.357 millones de personas, con una clase media también en crecimiento y con hábitos de consumo y estilos de vida que Colombia está en capacidad de atender.

Actualmente, el consumo de café se encuentra limitado a algunos nichos de mercado asociados con niveles de ingreso medio-alto. Sin embargo, se espera que a término medio, este producto conquiste otros subsectores, tanto en el sector industrial como en el ámbito comercial, pues gran parte del mercado aún no ha sido cubierto y existe una amplia franja de la población por conquistar.

En la continuación de este artículo en la próxima edición de la Revista Digital Mundo Asia Pacífico se hablará en específico sobre preferencias del mercado de café en China, los gustos y exigencias del consumidor asiático y otras características importantes; todo esto con el fin de ubicar al productor colombiano en el esquema de consumo chino. Además, se mostrarán algunos modelos de éxito de iniciativas colombianas dentro del gigante asiático, en donde se hablará de las estrategias específicas y métodos de inserción en el mercado. Se abordarán mediante un análisis las debilidades, oportunidades, fortalezas y amenazas que afrontaría Colombia para incrementar el posicionamiento de su café en el mercado chino. 


\section{Referencias}

- Arias, C., \& Tristán, A. (2008). Oportunidades para el café en China. Informe de visita al mercado, PROCOMER. Obtenido de http://servicios.procomer.go.cr/aplicacion/civ/documentos/Cafe\%20en\%20 China.pdf

- Barlow, N. (22 de Octubre de 2013). The State of Domestic Coffee Production in China. Recuperado el Octubre de 2014, de China Briefing: http://www.china-briefing.com/news/2013/10/22/the-state-ofdomestic-coffee-production-in-china.html

- Café de Colombia. (05 de 2012). China, un interesante mercado en crecimiento para el café. Recuperado el 10 de 2014, de http://www.cafedecolombia.com/bb-fnc-es/index.php/comments/china_un_ interesante mercado_en crecimiento_para_el_cafe/

- Café de Colombia. (n....). $\bar{M}$ arcas $100 \%$. Recuperado el 10 de 2014, de http://www.cafedecolombia. com/particulares/es/el_cafe_de_colombia/marcas_100/

- Centro de Comercio Internacional. (01 de 2011). La guía del café. Obtenido de CHINA (Hong Kong y Macau inclusos): http://www.laguiadelcafe.org/guia-del-cafe/los-mercados-del-cafe/ China/?menulD $=2934$

- Centro de Comercio Internacional. (2013). Bilatertal Trade: Colombia and China. Recuperado el Octubre de 2014, de Trade Map.: http://www.trademap.org/Bilateral.aspx

- Chen, L., \& Lombaerde, P. (2013). Reposicionamiento de los productos "hechos en China" en las cadenas de valor globales y regionales. En E. Vieira, La transformación de China y su impacto para Colombia (págs. 107-141). Bogotá: Colegio de Estudios Superiores de Administración.

- Datos Macro. (2013). Datosmacro. Obtenido de http://www.datosmacro.com/demografia/poblacion/ china

- De Smet, W. (3 de Noviembre de 2013). Yunnan, Chinese province famous for tea, now looks to coffee. Recuperado el Octubre de 2014, de South China Morning Post : http://www.scmp.com/news/china/ article/1346182/yunnan-chinese-province-famous-tea-now-looks-coffee

- Duarte, R. (2013). Reflexión final: Hacia la consolidación de la asociación de cooperación integral (ACI) Colombia - China. En E. V. Posada (Ed.), La transformación de China y su Impacto para Colombia.

- El Colombiano. (n.d.). El Colombiano. Obtenido de Proexport identifica 16 productos para China: http:// www.elcolombiano.com/BancoConocimiento/P/proexport_identifica_16_productos_para_china/ proexport identifica 16 productos para china.asp

- Espresso \& Coffee Guide. (s.f.). Chinese Coffee.Recuperado el Octubre de 2014, de Espresso \& Coffee Guide: http://www.espressocoffeeguide.com/gourmet-coffee/asian-indonesian-and-pacific-coffees/ chinese-coffee/

- Euromonitor. (05 de 2012). Pronóstico de crecimiento de la categoría Café en China (2011 - 2016). Recuperado el 10 de 2014, de Café de Colombia: http://www.cafedecolombia.com/bb-fnc-es/index.php/ comments/china_un_interesante_mercado_en_crecimiento_para_el_cafe/

- Euromonitor. (2014). Coffee In China.

- Federación Nacional de Cafeteros de Colombia. (2013). Federación Nacinal de Cafeteros. Obtenido de Comportamiento de la Industria Cafetera Colombiana: http://www.federaciondecafeteros.org/static/files/ Informe Industrial 2013 Web.pdf

- Feliciano, J. (14 de Enero de 2013). Nestlé's New Coffee Product in China. (Euromonitor, Entrevistador)

- Firsd Tea. (10 de diciembre de 2013). Slideshare. Obtenido de China's Tea: Trends and Growth 20122013: http://es.slideshare.net/FirsdTea/chinas-tea-trends-and-growth-20122013

- Gibson, D.-T. (10 de Abril de 2013). Can Coffee Make Yunnan a Model for Chinese Agricultural Reform?Recuperado el Octubre de 2014, de New Security Beat: http://www.newsecuritybeat. org/2013/04/coffee-yunnan-model-chinese-agricultural-reform/

- International Trade Center. (2013). Comercio actual y potencial entre Colombia y China. Recuperado el 10 de 2014, de http://www.trademap.org/Bilateral TS.aspx?nvpm=3\%7C170\%7C\%7C156\%7C\%7C0901\%7 C\%7C\%7C6\%7C1\%7C1\%7C2\%7C2\%7C1\%7C1\%7C1\%7C1

- Infusionistas. (10 de Enero de 2011). China entra en el mercado del café. Recuperado el Septiembre de 2014, de Infusionistas: http://infusionistas.com/cafe/china-entra-en-el-mercado-del-cafe/

- International Trade Centre . (2010). The Coffee Sector In China: An overview of production, trade and Consumption.

- Kwong, M.-K. (03 de Noviembre de 2013). Yunnan, Chinese province famous for tea, now looks to coffee. South China Morning Post.

- Legiscomex. (Octubre de 2010). Normativa Agricola China. Recuperado el Octubre de 2014, de Legiscomex: http://www.legiscomex.com.ezproxy.eafit.edu.co/BancoConocimiento/N/normativaagricola-china/normativa-agricola-china.asp

- Liu, B. (28 de Enero de 2012). Yunnan's Caffeine Rush: For all the Coffee in China. Recuperado el Octubre de 2014, de The Economist: http://www.economist.com/node/21543580

- MarketLine. (Noviembre de 2013). Hot Drinks Industry Profile: China. Obtenido de Hot Drinks Industry Profile: China.

- National Bureau of Statistics of China. (2013). Statistical Communiqué of the People's Republic of China on the 2013 National Economic and Social Development.

- Organización Internacional del Café . (2013). Café en China . Belo Horizonte, Brasil.

- Ovalle, L. (2013). Tendencias del consumidor chino. En E. V. Posada, \& E. V. Posada (Ed.), La 
transformación de China y su impacto para Colombia . Colombia: CESA.

- Proexport. (2008). Guia para exportar a China.

- $\quad$ Proexport. (Noviembre de 2012). Un mercado de oportunidades. China.

- Proexport. (2014). Oportunidades de Negocio en China: Oportunidad café especial. Recuperado el Octubre de 2014, de Proexport: http://www.proexport.com.co/node/1108?page $=66$

- Roast Magazine. (2013). China Struggles to Improve Coffee Quality Despite Rising Domestic Demand. Daily Coffee News by Roast Magazine.

- Roldán-Pérez, A., Gonzalez- Perez, M. A., Thu Huong , P., \& Ngoc Tien, D. (s.f.). Coffee cooperation and Competition: A comparative study of Colombia and Vietnam .

- The World Bank. (2013). The World Bank.Obtenido de China | Data: http://data.worldbank.org/country/ china

- Wan, X. (3 de Noviembre de 2013). Yunnan, Chinese province famous for tea, now looks to coffee. Recuperado el Octubre de 2014, de South China Morning Post : http://www.scmp.com/news/china/ article/1346182/yunnan-chinese-province-famous-tea-now-looks-coffee 